\title{
Application of Associative Teaching Strategy in College English Vocabulary Teaching
}

\author{
Bo Liu \\ School of Applied Technology, The University of Science and Technology Liaoning, Anshan, China \\ Email: liubo@126.com
}

Received 11 May 2016; accepted 12 June 2016; published 15 June 2016

Copyright (C) 2016 by author and Scientific Research Publishing Inc.

This work is licensed under the Creative Commons Attribution International License (CC BY). http://creativecommons.org/licenses/by/4.0/

c) (7) Open Access

\begin{abstract}
Vocabulary teaching is very important in college English teaching. Although traditional vocabulary teaching costs a lot of time and effort, the actual teaching effect is not so good. The so-called associative teaching is to deepen grammar and cultural connotation from the perspective of form, sound and meaning in its essence. This article has analyzed the problems exist in college English vocabulary teaching and proposed the application countermeasures of associative teaching strategy in college English vocabulary teaching starting from the mode and importance of associative teaching strategy, which has laid foundation for improving the efficiency of college English vocabulary teaching.
\end{abstract}

\section{Keywords}

\section{Associative Teaching Strategy, College English, Vocabulary Teaching, Application} Countermeasures

\section{Introduction}

The continuous economic and social development has prompted the increasingly frequent foreign exchanges, and English is playing a more and more important role in communication. The college stage is a critical period for students' development, and the important turning point of learning and work. Students need to seize time effectively and enrich their own knowledge constantly, to improve their employment competitiveness. Pronunciation, grammar and vocabulary are the three important factors of language learning, playing an important role in language learning (Zhang, 2012). As an important carrier of language learning, vocabulary plays a very important role in communication. In the process of English learning, the quantity of vocabulary has become an important restriction factor. Moreover, the new words emerge in an endless stream. As a result, students not only have to master the basic vocabulary, but also shall memorize large number of strange words, which has raised higher requirements for college English vocabulary teaching. 


\section{Associative Teaching Mode}

Actually, the so-called association refers to the psychological activity process of associating with one subject from another one, belonging to a form of human thinking and understanding (Wei, 2010). Connection exists in all subjects. Although there may not be certain association between two subjects, human subjective initiative plays a very important role in it. Students' divergent thinking ability can be improved through association ability, so that they can grasp the vocabulary features accurately and give full play to their imagination and associate with relevant roots or images, thus the profound impression can be formed in students' mind, which is beneficial to improve their vocabulary memory ability. Associative teaching in vocabulary teaching includes many contents such as pronunciation, meaning and morphology, requiring students to master not only the correct way of pronunciation and spelling, but also to grasp the nature of vocabulary and ways of vocabulary application, etc., which has enhance the application efficiency of vocabulary. In the process of vocabulary learning, pronunciation is a very complicated problem, even a stress can directly affect the lexical meaning, and thus the pronunciation is required to be valued. For example, give play to students' imagination after reading a word, to make them think of some associated letters, and then conduct sufficient imagination and summary, so that the association mode combining pronunciation and spelling can be formed. Meaning plays an important role in vocabulary learning. In the process of memorizing meaning, mechanical memory shall be avoided by all means, to encourage students use their imagination to make lexical meaning concrete. For instance, when memorizing the word "happy”, the expression must be happy (Shi, 2012). And in the process of pronunciation explanation, students' impression can be deepened by combining with meaning and image, to guide students to form the association learning mode of pronunciation and meaning. Associative teaching mode is helpful to deepen students' vocabulary learning impression. Grasp the vocabulary in terms of whether pronunciation or meaning, to improve students' imagination and association ability, and cultivate students' independent training ability of vocabulary and the practical application ability.

\section{Problems Exist in College English Vocabulary Teaching}

\subsection{Incomplete Cognition of Vocabulary Teaching}

College English teachers are often one-sided in terms of vocabulary teaching cognition in actual teaching process, as they think that students just need to listen to the pronunciation and associate to the spelling, and teachers just need to offer a simple explanation of the words' practical meaning, which makes students think that words are independent, and their learning of vocabulary is just the fundamental cognition of words. As a result, students cannot conduct wording and phrasing flexibly, making the expression in English present the negative transfer of Chinese, resulting in students' lack of English translation ability and writing ability. There will be misunderstanding if the words are memorized only by virtue of Chinese interpretation (Wu, 2013). In the process of examination, students just answer questions relying on the meaning, making the actual learning effect not very ideal. Words are not independent, and if teachers just explain the meaning of the words, students will just memorize part of the word meaning and example sentences, without giving full consideration to the problems of pronunciation, meaning and spelling, resulting in vocabulary teaching's lack of connection and systematicness. In English vocabulary teaching process, the proper interpretation shall be offered, so that students can fully understand the words, avoiding mechanical application, thus students can memorize words and English sentences better with stronger comprehension and memorizing ability.

\subsection{Influence of Traditional Education Concept}

Traditional Chinese culture is well developed, having profound influence on education. And the traditional education concept also has great impact on English teaching. In the long term, students pay more attention to knowledge accumulation in the process of English learning. The pure memory has become a single learning ability. The inheritance learning style makes some students cannot fully adapt to college English learning mode and continue to use the traditional way of learning, namely, to pay more attention to learning and accumulation of knowledge but not the application of knowledge. Wrong learning concept will directly affect the actual learning efficiency. In the process of learning English, students' understanding and absorptive capacity shall be cultivated with emphasis, which will need to cultivate students' practical ability. Due to the influence of traditional concept of learning, students have always been in a passive position, and they just take notes and memorize words, while 
neglecting to improve their own English language skills. Although some teachers guide students to understand article with high requirement, they neglect vocabulary teaching as they pay more attention to students' learning of paragraph and sentence groups. In the process of learning, if students don't know the key words or are not familiar with the key words, the accuracy of their understanding toward the article will be affected greatly. Some other teachers overemphasize students' oral English learning and listening in the classroom teaching process. If the students have exercised the speaking skills and listening skills, but fail to accurately grasp the expressive vocabulary, then they are unable to express fully. As a result, the actual teaching effect is not very ideal.

\subsection{Problems Exist in Words Memorizing}

In the actual teaching process, many students have the learning-weariness, especially in English vocabulary learning. The efforts students have paid for vocabulary is not proportional to the specific performance. Students cannot remember the words although they have spent a lot of time, and they are at a loss in writing or reading. And although students remember the words temporarily, they will forget them quickly, so the students are affected greatly in terms of their confidence. Most of the students just memorize the words mechanically without mastering the memory law, and fall into the recite cycle, so the actual effect is not very ideal. In traditional learning process, teachers have always adopted the simplified explanation way, namely, teachers lead students to read the words, and then list the meanings of the words as well as the specific using methods. Students have always been in a passive position in the classroom, as they just take notes and then recite. Over time, the students lose interest in vocabulary learning, and practical learning efficiency is not very ideal. In the process of vocabulary learning, due to the restrictions of language learning environment and their own learning style, students tend to only remember the word meaning, but ignore the particular collocation of words. Therefore, their quantity of vocabulary hasn't been improved after reciting and the word memory efficiency is so good.

\section{Importance of Associative Teaching Strategy in College English Vocabulary Teaching}

\subsection{The Need for Modern Society Development}

As an essential part of human ability, everyone has the imagination and association ability. As a result, associative teaching has become an important way of vocabulary teaching in colleges and universities, meeting modern college students' learning requirements, and it has also become the indispensable process in college English vocabulary teaching. College students need to pay attention to discover their own imagination and association ability, expand their own capacity, so as to inspire their learning ability. In the process of vocabulary memorizing, the principle of "using the minority to bring along the majority" shall be followed to improve the actual learning effect. In teaching activities, considering the students already have a certain English vocabulary accumulation, teachers need to guide students to use the concrete memory method, to classify the words with same characteristics. The classification process shall be systematic, layered and associated, to cultivate students' divergent thinking taking full use of associative ability, thus to summary the words. Follow the principle of drawing references, construct the systematic vocabulary learning network, and improve students' ability of mastering vocabulary (Jiao, 2014).

\subsection{The Need for Cultivating Students' Comprehensive Language Ability}

In the process of college English vocabulary teaching, students' associative thinking ability and divergent thinking ability have very important influence on students' vocabulary memory. Students can quickly grasp the word pronunciation and application methods through vertical, horizontal and comprehensive association to improve vocabulary memory efficiency, so that students can better understand the meaning of the words, and improve students' sensitivity of English vocabulary learning as well as learning motivation. At the same time, associative teaching is conducive to create a more relaxed and pleasant learning atmosphere for students, enabling students to better feel the English vocabulary (Zhang, 2013). As an important part of human consciousness, association ability and imagination ability are of the advanced consciousness, having strong expression in the aspect of image, and in the specific teaching activities, teachers can extend students' words using the words that have been mastered, which is helpful to improve vocabulary learning efficiency. In vocabulary teaching process, the reasonable imagination can be expanded through the combination of sound, form and meaning, and they can 
be expressed more vividly, thus students can learn better in a relaxed environment.

\section{Application Countermeasures of Associative Teaching Strategy in College English Vocabulary Teaching}

\subsection{Pay Attention to Students' Life Relevance}

In the teaching process of college English vocabulary, teachers can associate students' daily life with the vocabulary teaching effectively, to improve students' memory ability starting from their concrete reality in combination with their life experience. In the teaching process, teachers need to create a more relaxed learning environment and learning atmosphere for students, to stimulate students' vocabulary learning desire of association. For example, teachers can encourage students give full play to their imagination in combination with lexical characteristics. For instance, while teaching the word "sheep", teachers can use the game of "Counting Sheep" we often play when we were young, thus students can integrate into the classroom learning better and the traditional “cramming” teaching can be changed, improving students' learning enthusiasm, and it is helpful to improve students' classroom learning efficiency.

\subsection{Cultivate Students' Good Learning Habit}

In the process of college English vocabulary learning, students' habit of consulting dictionary shall be cultivated, and encourage students to check at any time and remember at any time, thus to form a good vocabulary teaching habit. Along with the increasingly foreign exchanges, there are more and more opportunities for people to use English (Wang, 2013). But because of the quantity of vocabulary and the restrictions in terms of English level, people often encounter some unfamiliar words. So they need to consult the dictionary and take notes once they encounter the words, thus they will master some words subtly, saving a lot of time of memorizing them. At the same time, their English learning habit has also been regulated, which is helpful to improve students' vocabulary accumulation. For example, teachers can encourage students to watch American TV series, such as, Friends and Family Album USA and so on, ask them to take down the words they don't know. Teacher can hold salon activities regularly, make the students to communicate freely, and exchange their own learning experience, rendering students enough time and space for independent learning, to enhance their vocabulary learning interest and learning enthusiasm, thus to improve the efficiency of vocabulary teaching (Zhang, 2013).

\subsection{Pay Attention to the Combination of Sound and Meaning}

In the process of college English teaching, students' vocabulary memory is generally not so good, as they are difficult to remember these words. Because the student did not combine the pronunciation, meaning and form effectively, so there is the phenomenon of separation of sounds and forms. As the material shell of vocabulary, pronunciation is an important form of language vocabulary and grammar. English belongs to the phonetic writing, and regularity also exists in pronunciation, as pronunciation and spelling rules are very stable. The memory can be optimized through the combination between sound and form, to deepen the memory effect. If students rely on memory purely, then they cannot combine sound and form effectively and there will be obstacle in terms of memory. The separation of sound and form make students memorize words in an isolated manner, being unable to master the law of letter combinations and the association (Hu, 2010). Students' level of vocabulary memory is affected greatly with poor memory quality. In vocabulary teaching process in colleges and universities, teachers should attach importance to cultivate students' English learning skills, master the pronunciation rules, grasp the syllable partition rules and various letters' pronunciation as well as master the combination skills of sound and form, thus students can master sound and form better, to realize the effective combination of sound, form and meaning. For example, in the process of teaching the word "see", teachers can encourage students to associate, for example, "e" is like human's eyes, which means to see. For instance, in the process of explaining the word "view", teachers can use "e" to guide students to make association, as "e" is like human's eyes meaning to see, so they can think of the meaning of "view". Through the sound-semantic association, students can grasp the vocabulary meaning better, with better actual application effect. For example, in the process of teaching of explaining "stammer", its pronunciation can be used to remember the word with better memory effect (Zeng, 2014). 


\section{Conclusion}

In the process of English vocabulary learning, associative teaching strategy is beneficial to improve English teaching efficiency. Teachers need to realize that the associative strategy is not almighty. They need to pay attention to the reasonable teaching design, emphasis the deep-level cognitive learning, and improve vocabulary application efficiency. In the process of vocabulary learning, students shall be guided to master English learning skills, improve language skills and communication skills, master the more effective learning strategies and look for the methods and skills that are more suitable for them, to enhance their English learning efficiency. Teachers need to make clear their important responsibilities, recognize the importance role of associative teaching in students' vocabulary learning, guide students to form the correct creative ability and imagination ability, stimulate their inspiration, enhance students' interest in English vocabulary learning, thus to create a more pleasant emotional experience for students. This paper conducts the targeted teaching in combination with students' actual condition aiming to improve classroom teaching efficiency, give effective play to the important role of associative teaching in English vocabulary teaching, to enhance classroom learning enthusiasm.

\section{References}

Hu, L. L. (2010). Application of Associative Strategy in English Vocabulary Teaching. Overseas English, No. 9, 20-21.

Jiao, W. J. (2014). Analysis of Application of Associative Strategy in College English Vocabulary Teaching. Family Education World: Innovative Reading, No. 2, 225-226.

Shi, H. P. (2012). Discussion on Application of Associative Strategy in College English Vocabulary Teaching. English Square: Academic Research, No. 10, 69-70.

Wang, Q. F. (2013). Analysis of Application of Associative Strategy in College English Vocabulary Teaching. Youthful Days, No. 23, 237-237.

Wei, H. (2010). Associative Memory Strategy of College English Vocabulary Teaching. Examination Weekly, No. 55, 109110.

Wu, Z. (2013). Associative Memory Strategy and College English Vocabulary Teaching. Journal of Hunan Industry Polytechnic, No. 6, 81-83.

Zeng, W. J. (2014). Discussion on Application of Association in College English Vocabulary Teaching. Time Education, No. 9, 152.

Zhang, L. (2012). Application of Vocabulary Associative Memory Strategy in Vocabulary Teaching in High School. Dalian: Liaoning Normal University.

Zhang, Q. (2013). Application of Associative Strategy in English Vocabulary Teaching. Science \& Technology Information, No. 12, 166 .

Zhang, S. F. (2013). Application of Associative Strategy in English Vocabulary Teaching. Journal of Teaching and Management, No. 8, 139-141. 